\title{
Description of a peculiar Rhithrogena nymph from the Iberian Peninsula (Ephemeroptera, Heptageniidae)
}

\author{
Michel Sartori ${ }^{1, *}$ and Samantha J. Hughes ${ }^{2,3}$ \\ 1 Museum of zoology, Palais de Rumine, Place Riponne 6, CH-1005 Lausanne, Switzerland. \\ 2 Departamento de Engenharia Florestal, Instituto Superior de Agronomia, Tapada da Ajuda, 1349-017 Lisboa, Portugal, \\ sammyno1@isa.utl.pt. \\ 3 Centre for Macaronesian Studies, University of Madeira, Penteada Campus, Funchal 9000-390, Portugal, sa- \\ mantha@uma.pt. \\ * Corresponding author: michel.sartori@vd.ch
}

\begin{abstract}
Description of a peculiar Rhithrogena nymph from the Iberian Peninsula (Ephemeroptera, Heptageniidae)

Recent collecting in southern Portugal (Algarve) let to the discovery of an unusual Rhithrogena that possibly belongs to the so-called Rh. sowai group. The nymph of the species is described but not named, and affinities and relationships with other members from the Iberian Peninsula are discussed.
\end{abstract}

Key words: Portugal, Rhithrogena, nymph, Rhithrogena sowai group, description.

\section{RESUMEN}

Descripción de una ninfa peculiar de Rhithrogena para la Península Ibérica (Ephemeroptera, Heptageniidae)

Una especie poco frecuente de Rhithrogena, que posiblemente pertenece al llamado grupo Rh. sowai ha sido descubierta en unos muestreos realizados recientemente en el sur de Portugal (Algarve). En este trabajo se describe la ninfa de la especie pero no se le da nombre. Se discuten también las relaciones y afinidades con otros miembros del género de la Península Ibérica.

Palabras clave: Portugal, Rhithrogena, ninfa, grupo de Rhithrogena sowai, descripción

\section{INTRODUCTION}

With ca 70 species known in Europe (Caucasus excluded), the mayfly genus Rhithrogena is the most diversified among Ephemeroptera. It seems to present a high degree of endemicity, in peculiar in mountain ranges (Pyrenees, Alps, Carpathians), in Southern Peninsulas (Iberian, Italian and Balkanise) as well as on Mediterranean islands.

Traditionally (Sowa, 1984), Rhithrogena nymphs are separated in species groups accor- ding to some reliable features, such as the shape of the $7^{\text {th }}$ gill, the shape of the lateral sclerites of the $1^{\text {st }}$ abdominal sternite, the plica on the $1^{\text {st }}$ gill or even the presence or absence of dark spots on the femora (e.g. Sartori \& Oswald, 1988; Tomka \& Rasch, 1993; Soldán \& Landa, 1999).

The genus Rhithrogena in the Iberian Peninsula is represented by ca 20 species belonging to the so called alpestris group ( 2 species), hyphenization group (5 species), loyolaea group (1 species), semicolorata group (8 species) and 
sowai group (3 species), with one species ( $R h$. catalaunica Navás, 1916) not assigned to any group because inadequately described at the imaginal stage only. At the moment, no species of the hybrida-or the hercynia group (as defined by Sartori \& Oswald, 1988) has ever been mentioned from this Peninsula outside the Pyrenees (Vinçon \& Thomas, 1987). Among the species present, those of the $R h$. sowai group are the less well known. This group encompasses 6 species in Europe and only a single one is known at the nymph stage: Rh. buresi Sowa, 1973 from Bulgaria (Sowa, 1973). Therefore, no immature stages of those present in the study area, namely Rh. castellana Navás, 1927, Rh. daterrai Sowa, 1984, or Rh. monserrati Alba-Tercedor \& Sowa, 1986 are known.

During a research program led by the junior author in Southern Portugal (Odelouca River, Arade watershed, Algarve), some peculiar Rhithrogena nymphs have been caught which belong neither to the diaphana-semicolorata groups nor to the alpestris-loyolaea groups, but could represent the nymphs of a species of the sowai-group. Due to the scarcity of data on this group in Spain and Portugal, we think of interest to describe it, its naming pending further evidence.

\section{MATERIAL \& METHODS}

The material has been collected within the framework of the characterisation and requalification of riparian corridors along the Odelouca River, Algarve, Portugal. This project focuses on the restoration of the extensive and valuable riparian corridor following the construction of a dam and reservoir for augmenting water supply in the Algarve.

Collections by kick samplings have been done in station Odelouca $21\left(8^{\circ} 29^{\prime} 40^{\prime \prime} \mathrm{W}, 37^{\circ} 15^{\prime} 17^{\prime \prime} \mathrm{N}\right.$, $50 \mathrm{~m}$ a.s.1.), on March 8, 2005, S.J. Hughes coll: Among the macroinvertebrates were 3 nymphs of the species described below. The specimens are kept in $75^{\circ}$ ethanol and deposited in the mayfly collection of the Museum of zoology, Lausanne Switzerland; one nymph has been partially mounted on slide in Canada balsam.

\section{RESULTS}

Rhithrogena sp. (sowai group?)

Size: body length up to $9.5 \mathrm{~mm}$ (not full grown nymph)

Head medium brown, antennae with scape and pedicel light brown, flagellum yellowish.

Pronotum medium brown with a median longitudinal thin white band. Mesonotum the same, the band larger. Femora light brown, with a distinctive dark spot in the middle of the anterior face, especially well marked on the fore femora. Tibiae and tarsi yellowish. Abdominal tergites medium brown, becoming darker on the last two segments.

Mouthparts: Labrum expanded laterally, ca 3.2 times larger than long, without antero-median emargination and with a robust seta at mid-length (Fig. 1a). Mandibles with inner incisor half the length of the outer one (Fig. 1b). Row of setae between incisor and mola. Maxillae: Crown of the galea-lacinia composed of 9-10 comb-shaped setae, the median ones with 8-10 teeth (Fig. 1c). Labium showing no discriminating characters.

Legs: Ratio length/width of fore-, middle and hind femora: 2.6, 3.2 and 2.7 respectively. Fore femora with a row of long and somewhat spatulate setae on the dorsal margin; ventral margin with scattered short and blunt setae (Fig. 1d). Setae on the anterior face rather short, with divergent margins and truncate apex (Fig. 1e). Tibiae and tarsi almost without setae, except a few short and acute setae on the ventral margin of the tibiae. Tarsal claw with two well developed teeth. Middle legs the same. Hind legs the same, except a crown of thick and pointed setae at the apex of the tibiae (Fig. 1f).

Abdomen: Lateral sclerites of the first sternite rectangular, their anterior margin almost perpendicular to body axis. Middle abdominal tergites with thin setae, posterior margin constituted by long and pointed teeth of regular size, about 3.5 times as long as wide at base (Fig. 1g).; submarginal microdenticles absent. First gill with crenulated margin, plica triangular with slightly concave apex (Fig. 1h). Gills II-VII all moderately crenulated (Figs. 1 i-j). 

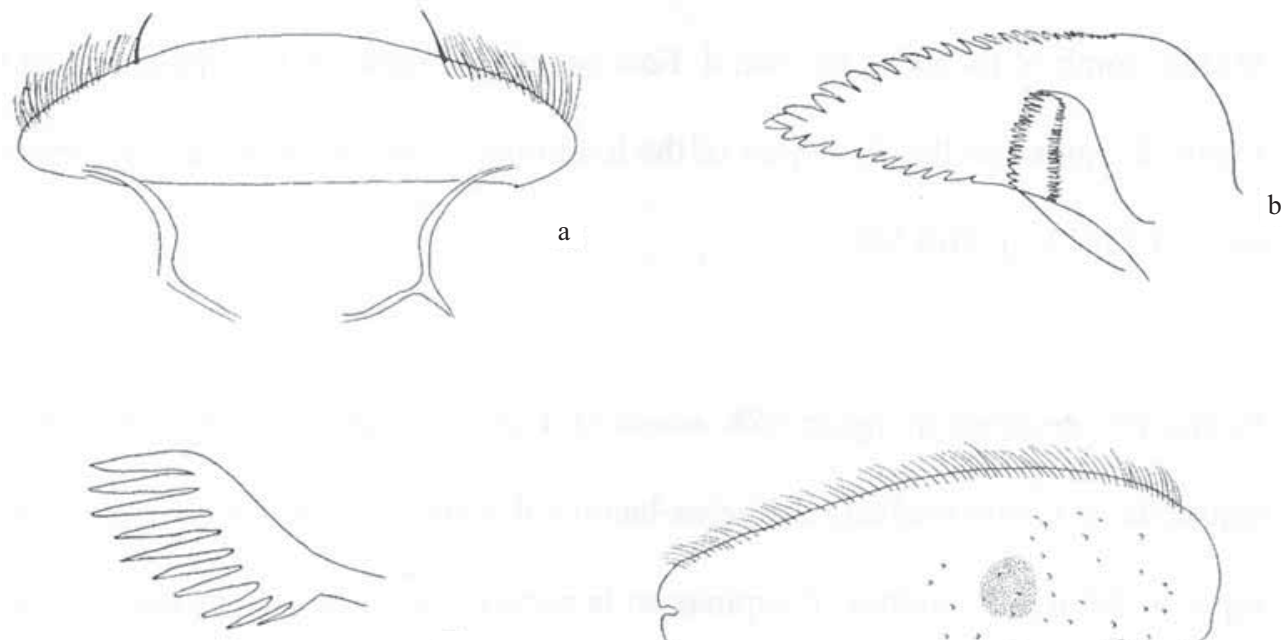

$\mathrm{c}$
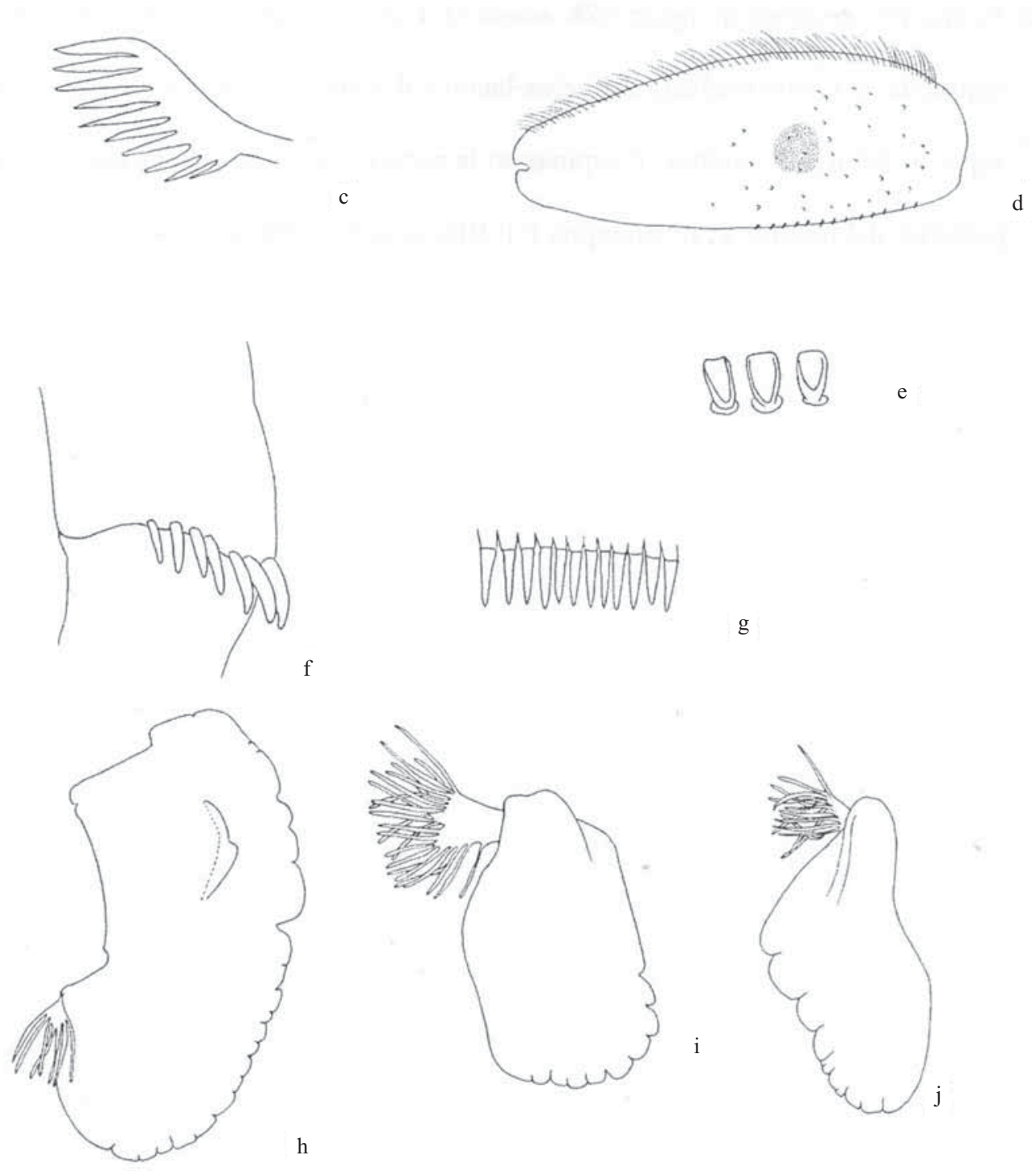

g
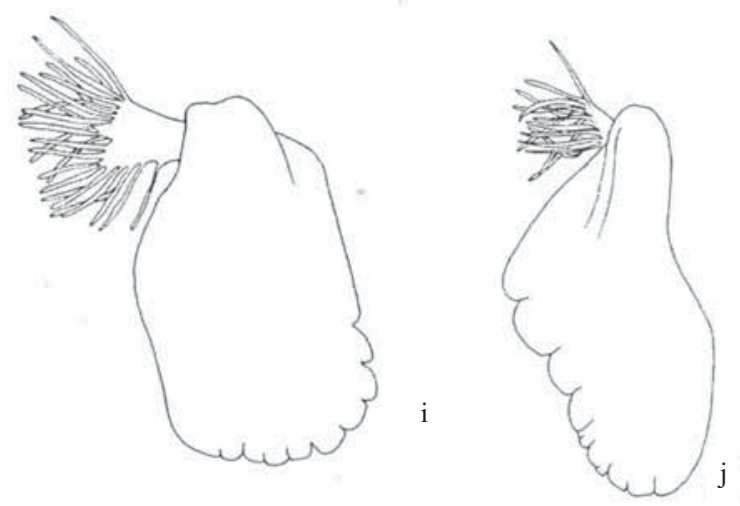

Figure 1. Rhithrogena sp. (groupe Rh. sowai ?). a-j: Nymph. a: Labrum; b: Left mandible; c: Middle comb of the galea-lacinia; d: Fore femur; e: Scales on the upper face of fore femur; f: Spines on the distal part of the hind tibia; g: Posterior margin of tergite V; h: Gill I; i: Gill V; j: Gill VII. Rhithrogena sp. (grupo Rh. sowai ?). a-j: Ninfa. a: Labro, b: Mandíbula izquierda; c: Carda mediana de la galea-lacinia; d: Fémur anterior; e: Escamas de la cara superior del fémur anterior; $f$ : Espinas de la parte distal de la tibia posterior; g: Margen posterior del tergito V; h: Branquia I; $i$ : Branquia V; j: Branquia VII. 


\section{DISCUSSION}

\section{Affinities}

According to Sowa $(1973,1984)$ the nymphs of the $R h$. sowai group can be distinguished mainly by:

- Lateral sclerites of the first abdominal sternite quadrangular, their anterior margin perpendicular to the body axis or slightly turned backwards;

- All gills moderately crenulated

- Plica on the first gill triangular

The first two features are also common to the Rh. hybrida-hercynia groups, but the plica of these nymphs is never triangular, being generally limited to a thicker area.

The specimens described here fit the diagnosis of the group, having the three characters altogether. So, they are likely to belong to a species of the $R h$. sowai group. But which species?

According to what we know about Rhithrogena ontogenesis, when dark spots are present on the femora of the nymph, they are also present in the winged stages, because it involves pigmentation of the epidermis and not of the chitin. The three species occurring in the Iberian peninsula, Rh. castellana, Rh. daterrai, Rh. monserrati, lack this distinctive pattern, contrary to the nymphs described here (see Sowa, 1984; Thomas \& Sartori, 1985; Alba-Tercedor \& Sowa, 1986). We therefore can assume that they do not belong to one of these species, and constitute indeed a fourth Iberian species of the group.

A comparison with the type material of $R h$. buresi confirms that our specimens are close to those from Bulgaria, but differ in several aspects, e.g. the shape of the labrum and of the mandibles, or the number of teeth on the comb-shaped setae of the galea-lacinia. The nymphs of the two other species, namely Rh. sowai Puthz, 1972 (Albania, Bulgaria, Romania) and Rh. jacobi Braasch \& Soldán, 1988 (Bulgaria) are unknown but it is to be expected that they possess also dark spots on the femora according to the adults.

It remains the possibility that our material belongs to a North African species. Currently, five Rhithrogena species are known from Morocco, only $R h$. mariae Vitte, 1991 being known at the nymph stage and belonging to the $R h$. semicolorata group (Vitte, 1991). Rh. ryszardi Thomas \& Soldán, 1987 belongs to the Rh. germanica subgroup of $R h$. semicolorata group (Thomas et al., 1987), and the three other species have not been assigned to any group (Thomas \& Mohati, 1985; Dakki \& Thomas, 1986; Thomas \& Bouzidi, 1986). Based on the shape of the male genitalia, none of them seem to belong to the $R h$. sowai group.

Therefore, it is most likely that the nymphs described here belong to a new species. Further material will be needed, including male imagos, to confirm this hypothesis.

\section{Ecology}

Nymphs of Rhithrogena sp (sowai group?) were collected from just two closely located lowland riverine sites in the Odelouca basin (within approximately $2-3 \mathrm{~km}$ of each other) situated downstream of the Odelouca dam. The nymphs appear to be associated with, low energy, shallow sites, with a wide $(>45 \mathrm{~m}$ bankfull width) meandering channel. Recorded environmental conditions at these sites include a predominantly low energy flow regime, with gravel like substrates overlain by silts and sand. The growth of filamentous algae and Ranunculus is exceptionally high, further reducing the rate of downstream flow. Although these nymphs are clearly associated with running water, the prevailing conditions at these sites contrast strongly with the riffle habitat of most other Rhithrogena species, such as Rh. semicolorata or Rh. germanica (Elliott et al., 1988; Lubini \& Sartori, 1994; Hanquet et al., 2004).

\section{ACKNOWLEDGMENTS}

We are indebted to our colleague Malgorzata Klonowska (Krakow) for the long term loan of the type material of the late Prof. R. Sowa, including the nymph of $R h$. buresi used here for comparative purposes. The junior author was funded by a post 
doctoral fellowship grant from the Fundação de Ciêcias e Tecnologia. Comments by Alain Thomas (Toulouse) and an anonymous reviewer help to improve the manuscript.

\section{REFERENCES}

ALBA-TERCEDOR, J. \& R. SOWA. 1986. Two interesting Rhithrogena Eaton from Spain: $R$. thomasi sp.n. and R. monserrati sp.n. (Ephemeroptera: Heptageniidae). Aquatic Insects, 8: 185-189.

DAKKI, M. \& A. G. B. THOMAS. 1986. Rhithrogena ayadi n.sp., Ephéméroptère nouveau du Moyen Atlas marocain (Heptageniidae). Annales de Limnologie, 22: 27-29.

ELLIOTT, J. M., U. H. HUMPESCH \& T. T. MACAN. 1988. Larvae of the British Ephemeroptera: a key with ecological notes. Freshwater Biological Association, Scientific Publications, 0(49): 1-145.

HANQUET, D., M. LEGALLE, S. GARBAGE \& R. CEREGHINO. 2004. Ontogenetic microhabitat shifts in stream invertebrates with different biological traits. Arch. Hydrobiol., 160: 329-346.

LUBINI, V. \& M. SARTORI. 1994. Current status, distribution, life cycle and ecology of Rhithrogena germanica Eaton, 1885 in Switzerland: preliminary results (Ephemeroptera, Heptageniidae). Aquat. Sci., 56: 388-397.

SARTORI, M. \& R. OSWALD. 1988. Rhithrogena grischuna nov. sp., a new mayfly species from eastern Switzerland related to Rh. hercynia Landa, 1969 (Ephemeroptera; Heptageniidae). Annales de Limnologie, 24: 261-268.

SOLDÁN, T. \& V. LANDA. 1999. A key tho the Central European species of the genus Rhithrogena (Ephemeroptera: Heptageniidae). Klapalekiana, 38: 25-37.

SOWA, R. 1973. Notes sur quelques espèces paléarctiques de Rhithrogena Eaton (Ephemeroptera, Heptageniidae). Bulletin de l'Académie polonaise des Sciences Cl.II, 21: 21-26.

SOWA, R. 1984. Contribution à la connaissance des espèces européennes de Rhithrogena Eaton (Ephemeroptera, Heptageniidae). In: Proceeding of the fourth international conference on Ephemeroptera. V. Landa, T. Soldán \& M. Tonner, (eds.): 3752 Bechyne, CSAV.

THOMAS, A. G. B. et A. BOUZIDI. 1986. Trois Ephéméroptères nouveaux du Haut Atlas marocain (Heptageniidae, Baetidae, Leptophlebiidae). Bulletin de la Société d'Histoire Naturelle de Toulouse, 122: 7-10.

THOMAS, A. G. B. et A. MOHATI. 1985. Rhithrogena ourika n.sp., Ephéméroptère nouveau du Haut Atlas marocain (Heptageniidae). Annales de Limnologie, 21: 145-148.

THOMAS, A. G. B. et M. SARTORI. 1985. Rhithrogena gorrizi Navás, 1913 et Rh. castellana Navás, 1927: redescription des imagos (Ephemeroptera: Heptageniidae). Annales de Limnologie, 21: 65-70.

THOMAS, A. G. B., B. VITTE et T. SOLDÁN. 1987. Rhithrogena ryszardi n. sp., Ephéméroptère nouveau du Moyen Atlas (Maroc) et redescription de Rh. soteria Navás, 1917 (Heptageniidae). Annales de Limnologie, 23: 169-177.

TOMKA, I. \& P. RASCH. 1993. Beitrag zur Kenntnis der europäischen Rhithrogena-Arten (Ephemeroptera, Heptageniidae): R. intermedia Metzler, Tomka et Zurwerra, 1987 eine Art der alpestris-Gruppe sowie ergänzende Beschreibungen zu fünf weiteren Rhithrogena-Arten. Mitteilungen der Schweizerischen Entomologischen Gesellschaft, 66: 255-281.

VINCON, G. et A. G. B. THOMAS. 1987. Etude hydrobiologique de la Vallée d'Ossau (Pyrénées Atlantiques). I. Répartition et écologie des Ephéméroptères. Annales de Limnologie, 23: 95-113.

VITTE, B. 1991. Rhithrogena mariae n.sp., Ephéméroptère nouveau du Rif marocain (Ephemeroptera, Heptageniidae). Nouvelle Revue d'Entomologie, 8: 89-96. 